\title{
Contribution of biomarkers in the geochemical characterization of potential source rocks in northern Tunisia and their relationships with oil seeps
}

\section{T. HALLEK ${ }^{1 *}$, M. MONTACER ${ }^{1}$}

${ }^{1}$ Research unit of Geosystems, Georesources and Geoenvironnements (UR3G), Faculty of Sciences of Gabes, University of Gabes, 6072, Zrig, Gabes, Tunisia.

(* correspondance: tahanihallek@gmail.com)

$$
\text { Hydrocarbon seepage phenomenon is considerably }
$$
detected in Northern Tunisia. This study aims to analyze these oil/gas seeps and to know their genetic origin, using molecular biomarkers. This requires correlations with possible sources. According to their palaeogeographic positions, we have selected four source rocks; M'Cherga (Hauterivian-Barremian), Fahdene (Albian-Lower Cenomanian), Bahloul (Upper Cenomanian-Lower Turonian) and BouDabbous (Ypresian).

Oil/oil and oil/source rock correlations, using biomarkers and statistic data, provide origin identification of each seep, and allow to create a map of distribution seeps depending on their origins. This map shows two categories; the first located in the North including ypresian oil seeps with some Hauterivian-Barremian traces, and the second covering southern part, containing cretaceous seeps. Furthermore, this study has showed the confusion of hydrocarbon seeps nomination. Indeed, we have detected five samples of free bitumen preserved in their rock precursors. These indices are named hydrocarbon impregnations. 